\title{
Os Impactos das Mudanças na Demanda por Trabalho Qualificado sobre o Desemprego por Nível de Qualificação durante os Anos Noventa no Brasil
}

\author{
Maurício Cortez Reis
}

Sumário: 1. Introdução; 2. Fatos estilizados; 3.0 modelo; 4. Resultados empíricos; 5. Os impactos de choques agregados e relativos sobre o desemprego; 6. Conclusões; A. Descrição dos dados; B. Resultados com os parâmetros das curvas de salário obtidos com os rendimentos por hora; C. Resultados obtidos a partir das informações da PME.

O aumento da taxa de desemprego no Brasil durante a década de noventa foi muito mais intenso para os trabalhadores com níveis mais baixos de qualificação. O objetivo deste artigo é avaliar o papel das mudanças na demanda por trabalho qualificado para as diferenças observadas nas trajetórias do desemprego por nível qualificação. Para isso, é utilizado um modelo em que a economia está sujeita a choques agregados, que incidem sobre todos os tipos de trabalhadores da mesma forma, e choques relativos, que representam mudanças na estrutura da demanda por trabalho. Usando dados da PNAD (Pesquisa Nacional por Amostra de Domicílio) de 1990 a 1999 são estimados os parâmetros do modelo a partir do qual são calculados os impactos de cada um dos choques sobre as variações nas taxas de desemprego por nível de qualificação. De acordo com as evidências empíricas encontradas, choques relativos levaram a um aumento na demanda por trabalhadores qualificados em comparação com os semi-qualificados e os não-qualificados, resultando em uma redução do desemprego dos qualificados em relação aos demais grupos.

During the 1990's, Brazil experienced a remarkable increase in its unemployment rate, The intensity of this process was higher for unskilled and semiskilled workers than for skilled. The objective of this paper is to evaluate the role of skill-biased shifts in the structure of labor demand for the patterns of unemployment rate by skill. In order to do so, a model with two kinds of shocks, aggregate and relative, was used. The aggregate shocks are those that are equal 
to all skill groups, and the relative ones are related to labor demand structural changes. The parameters of the model were estimated using PNADs (Pesquisa Nacional por Amostra de Domicílio) data from 1990 to 1999. Then, the impact of each shock on unemployment rate by skill was evaluated. According to the evidence found in this paper, the demand for skilled workers increased compared to semi-skilled and unskilled, leading to a reduction on skilled workers relative unemployment rate.

Palavras-chave: Desemprego, Qualificação. Códigos JEL: J31, J40, J60.

\section{INTRODUÇÃO}

Durante a década de noventa, o desemprego no Brasil passou por alterações bastante significativas, tanto no seu nível quanto na sua estrutura. De uma taxa de desemprego extremamente baixa em 1990, próxima de 3\%, a economia brasileira passou para mais de $8 \%$ de desemprego em 1999. Nota-se também, que esse aumento foi muito maior para os trabalhadores com níveis mais baixos de escolaridade. Entre 1990 e 1999, a taxa de desemprego dos trabalhadores com até o primário incompleto aumentou em 6,4 pontos percentuais, enquanto para os indivíduos com pelo menos o segundo grau completo o aumento foi de 4,3 pontos percentuais.

Essas mudanças no desemprego ocorreram ao mesmo tempo em que a economia brasileira passou por alterações importantes. Na década de noventa, foi intensificado o processo de liberalização comercial, resultando na incorporação de novas tecnologias na produção e no aumento do comércio internacional. Nesse período, também foi implementado um intenso programa de privatizações, e o Plano Real conseguiu estabilizar a inflação. Alguns estudos apresentam evidências de que essas alterações influenciaram o comportamento do mercado de trabalho brasileiro através do aumento na demanda por trabalhadores mais qualificados (Menezes Filho e Rodrigues (2003), Fernandes e Menezes-Filho (2002) e Arbache e Corseuil (2004)). Mantendo os rendimentos relativos constantes, aumentos na demanda por trabalho qualificado, quando não são compensados por aumentos na oferta desse tipo de trabalhador, devem levar a taxas de desemprego mais altas para os trabalhadores menos qualificados em relação aos mais qualificados.

Outro fato importante é que o nível médio de qualificação da força de trabalho no Brasil era extremamente baixo no início da década de noventa. Em 1990, mais de um quarto dos indivíduos na População Economicamente Ativa (PEA) não possuíam sequer o primário completo. Pelas características do mercado de trabalho brasileiro e pela intensidade das mudanças ocorridas na economia durante a década de noventa, devemos esperar impactos significativos das alterações na estrutura da demanda por trabalho qualificado sobre o desemprego.

O objetivo desse artigo é analisar a importância das mudanças na estrutura da demanda por trabalho para o aumento mais acentuado da taxa de desemprego entre os trabalhadores não-qualificados no Brasil. Para isso, a força de trabalho é dividida em três grupos de qualificação. Com base no nível de escolaridade, os trabalhadores são classificados como: não-qualificados (trabalhadores com até o primário incompleto), semi-qualificados (com até o segundo grau incompleto) e qualificados (com pelo menos o segundo grau completo). Os impactos de mudanças na demanda relativa por trabalho sobre o desemprego são avaliados através de um modelo em que a economia está sujeita a choques agregados e relativos. Choques agregados incidem sobre todos os tipos de trabalhadores da mesma forma, enquanto choques relativos são representados por alterações nas produtividades dos grupos de qualificação.

Na literatura internacional existem evidências de que mudanças na estrutura da demanda por trabalho foram importantes para o comportamento do desemprego por nível de qualificação em alguns países desenvolvidos. Juhn et alii (1991) mostram que o aumento da taxa de desemprego nos Estados 
Unidos, nos anos setenta e oitenta, ocorreu apenas entre os trabalhadores menos qualificados. Para esses autores, esse fato é explicado pela queda na demanda por trabalho não-qualificado a partir dos anos setenta associada a uma oferta de trabalho bastante elástica para esse grupo. 0 deslocamento da demanda por trabalho teria reduzido os salários, o que por sua vez, teria provocado a diminuição da taxa de emprego. Layard et alii (1991) analisam as implicações das alterações na demanda relativa por trabalho para o aumento do desemprego nos países da OCDE (Organização para a Cooperação e Desenvolvimento Econômico). De acordo com os resultados encontrados por esses autores, os choques sobre a demanda relativa por trabalho qualificado aumentaram o desemprego dos não-qualificados em 2,95 pontos percentuais e reduziram o desemprego dos qualificados em 0,07 pontos percentuais. Além disso, essas alterações teriam sido responsáveis por $19 \%$ do aumento da taxa de desemprego total na OCDE entre as décadas de setenta e oitenta. Manacorda e Petrongolo (1999) investigam o comportamento do desemprego em cinco países (França, Reino Unido, Alemanha, Itália e Estados Unidos), e mostram que há uma tendência para o descasamento entre a demanda e a oferta por trabalho qualificado (skill mismatch) aumentar o desemprego dos não-qualificados e reduzir o desemprego dos qualificado. O skill mismatch foi particularmente importante no Reino Unidos e nos Estados Unidos, de acordo com as evidências de Manacorda e Petrongolo (1999), contribuindo com parte considerável do aumento do desemprego dos não-qualificados, assim como do desemprego total, entre as décadas de setenta e noventa.

A análise empírica implementada neste artigo utiliza os dados da PNAD (Pesquisa Nacional por Amostra de Domicílio) calculada pelo IBGE. A partir dessas informações, são estimados os parâmetros do modelo que permitem calcular os impactos dos choques sobre as variações nas taxas de desemprego de cada grupo de qualificação entre 1990 e 1999. De acordo com os resultados, ocorreu um aumento na demanda relativa por trabalhadores qualificados. Esse efeito foi compensado pelo aumento na oferta relativa desses trabalhadores, com o resultado final variando entre pequenas reduções ou aumentos na taxa de desemprego desse grupo. Os resultados para os trabalhadores não-qualificados indicam que a queda na demanda relativa foi bem mais forte do que a redução na oferta, levando a um aumento substancial na taxa de desemprego desse grupo. As mudanças na demanda relativa também foram desfavoráveis aos trabalhadores semi-qualificados, de acordo com o modelo. Como a participação desse grupo no total da força de trabalho apresentou um pequeno crescimento durante o período analisado, a taxa de desemprego também aumentou consideravelmente para esses trabalhadores. As evidências mostram também que os desajustes entre a demanda e a oferta de trabalho de cada grupo de qualificação teriam sido responsáveis por uma parcela entre $40 \%$ e $60 \%$ do aumento total da taxa de desemprego na década de noventa.

$\mathrm{O}$ artigo está dividido em cinco seções, além dessa introdução. Na seção 2, são descritos os principais fatos relacionados aos comportamentos de trabalhadores com diferentes níveis de qualificação no mercado de trabalho brasileiro, durante a década de noventa. A seção seguinte apresenta o modelo com três tipos de trabalhadores no qual a análise é baseada. Para resolver esse modelo é necessário imputar valores para os parâmetros das curvas de salário de cada grupo de qualificação e para a elasticidadesubstituição entre trabalhadores de diferentes grupos. A seção 4 apresenta os resultados estimados para esses parâmetros. Na seção 5 , são mostrados os resultados dos efeitos de choques agregados e relativos sobre as variações da taxa de desemprego por qualificação. A seção 6 apresenta as principais conclusões do trabalho.

\section{FATOS ESTILIZADOS}

Esta seção descreve as trajetórias da taxa de desemprego, dos rendimentos do trabalho principal e da composição da força de trabalho no Brasil entre os diferentes grupos de qualificação. A análise se baseia nos dados anuais da PNAD, calculada pelo IBGE.

A educação é utilizada como proxy para o nível de qualificação, e na análise descritiva dessa seção são definidos cinco grupos de acordo com o último ano completado: nenhum ano de estudo (analfabetos), 
entre 1 e 3 anos de estudo (primário incompleto, mas com alguma escolaridade), entre 4 e 7 (primário completo), entre 8 e 10 (ginasial completo) e 11 anos ou mais de estudo (secundário completo). Na avaliação dos efeitos de choques agregados e relativos sobre o desemprego, nas seções seguintes, os trabalhadores são divididos em: não-qualificados (entre 0 e 3 anos de estudo), semi-qualificados (entre 4 e 10 anos) e qualificados (11 anos ou mais) ${ }^{1}$.

Tabela 1 - Taxa de desemprego por escolaridade (\%)

\begin{tabular}{|c|c|c|c|c|c|c|}
\hline Ano & $\begin{array}{l}\text { Nenhum } \\
\text { ano }\end{array}$ & $\begin{array}{l}\text { Entre } 1 \text { e } 3 \\
\text { anos }\end{array}$ & $\begin{array}{l}\text { Entre } 4 \text { e } 7 \\
\text { anos }\end{array}$ & $\begin{array}{l}\text { Entre } 8 \text { e } \\
10 \text { anos }\end{array}$ & $\begin{array}{l}11 \text { anos ou } \\
\text { mais }\end{array}$ & Total \\
\hline 1981 & 2,94 & 3,62 & 3,53 & 3,64 & 2,42 & 3,24 \\
\hline 1982 & 2,53 & 2,83 & 3,51 & 3,49 & 2,15 & 2,93 \\
\hline 1983 & 3,55 & 3,98 & 4,68 & 5,03 & 3,27 & 4,10 \\
\hline 1984 & 2,98 & 2,97 & 3,90 & 3,79 & 2,56 & 3,27 \\
\hline 1985 & 1,77 & 2,53 & 3,01 & 3,34 & 2,17 & 2,59 \\
\hline 1986 & 1,31 & 1,60 & 1,94 & 2,17 & 1,65 & 1,76 \\
\hline 1987 & 2,15 & 2,62 & 3,09 & 3,21 & 2,24 & 2,69 \\
\hline 1988 & 2,42 & 3,07 & 3,01 & 3,89 & 2,29 & 2,86 \\
\hline 1989 & 2,19 & 2,44 & 2,81 & 3,06 & 1,74 & 2,41 \\
\hline 1990 & 2,55 & 2,92 & 3,32 & 4,11 & 2,33 & 2,99 \\
\hline 1992 & 6,01 & 5,90 & 6,11 & 7,02 & 4,59 & 5,76 \\
\hline 1993 & 5,20 & 5,47 & 5,96 & 6,48 & 4,00 & 5,31 \\
\hline 1995 & 5,78 & 5,47 & 5,44 & 6,36 & 4,00 & 5,18 \\
\hline 1996 & 6,91 & 6,52 & 6,69 & 6,72 & 4,48 & 6,02 \\
\hline 1997 & 7,38 & 7,07 & 7,35 & 8,00 & 5,20 & 6,73 \\
\hline 1998 & 7,76 & 8,06 & 8,26 & 8,92 & 5,84 & 7,50 \\
\hline 1999 & 9,03 & 9,27 & 8,97 & 9,67 & 6,67 & 8,35 \\
\hline \multirow{2}{*}{$\begin{array}{l}\text { Diferença } \\
90 \text { e } 81\end{array}$} & $-0,39$ & $-0,70$ & $-0,22$ & 0,47 & $-0,09$ & $-0,25$ \\
\hline & $(0.23)$ & $(0.22)$ & $(0.17)$ & $(0.29)$ & $(0.16)$ & $(0.09)$ \\
\hline \multirow{2}{*}{$\begin{array}{l}\text { Diferença } \\
99 \text { e } 90\end{array}$} & 6,48 & 6,35 & 5,65 & 5,56 & 4,34 & 5,36 \\
\hline & $(0.36)$ & $(0.32)$ & $(0.21)$ & $(0.32)$ & $(0.17)$ & $(0.11)$ \\
\hline
\end{tabular}

A tabela 1 apresenta as taxas de desemprego de 1981 a 1999 por nível de escolaridade. Entre 1981 e 1990 a taxa de desemprego aumentou apenas 0,25 pontos percentuais, com pequenas diferenças entre os grupos educacionais. Na década de noventa, porém, a taxa de desemprego aumentou 5,4 pontos percentuais, passando de $3 \%$ para $8,4 \%$. As diferenças entre os grupos de escolaridade também foram grandes. O grupo que apresentou a menor variação da taxa de desemprego foi aquele formado por indivíduos com 11 anos ou mais de estudo (4,34 pontos percentuais). Os dois grupos menos educados sofreram os maiores aumentos, de 6,48 e 6,35 pontos percentuais, respectivamente, e os indivíduos com escolaridade entre 4 e 7 anos e entre 8 e 10 anos apresentaram aumentos em torno de 5,6 pontos percentuais.

Como as mudanças no desemprego ocorreram basicamente na década de noventa, no restante do artigo a análise se concentra apenas nesse período. A figura 1 mostra as diferenças entre as taxas de desemprego dos indivíduos com 11 anos de escolaridade ou mais e as taxas dos demais grupos de 1990 a

\footnotetext{
${ }^{1}$ Essa classificação procurou agregar os trabalhadores em grupos relativamente homogêneos, considerando também o baixo nível educacional médio da força de trabalho no Brasil.
} 
1999. Nota-se claramente nesse gráfico, a queda acentuada no desemprego relativo dos mais educados, para as quatro comparações realizadas.

Figura 1 - Diferenças entre as taxas de desemprego por escolaridade

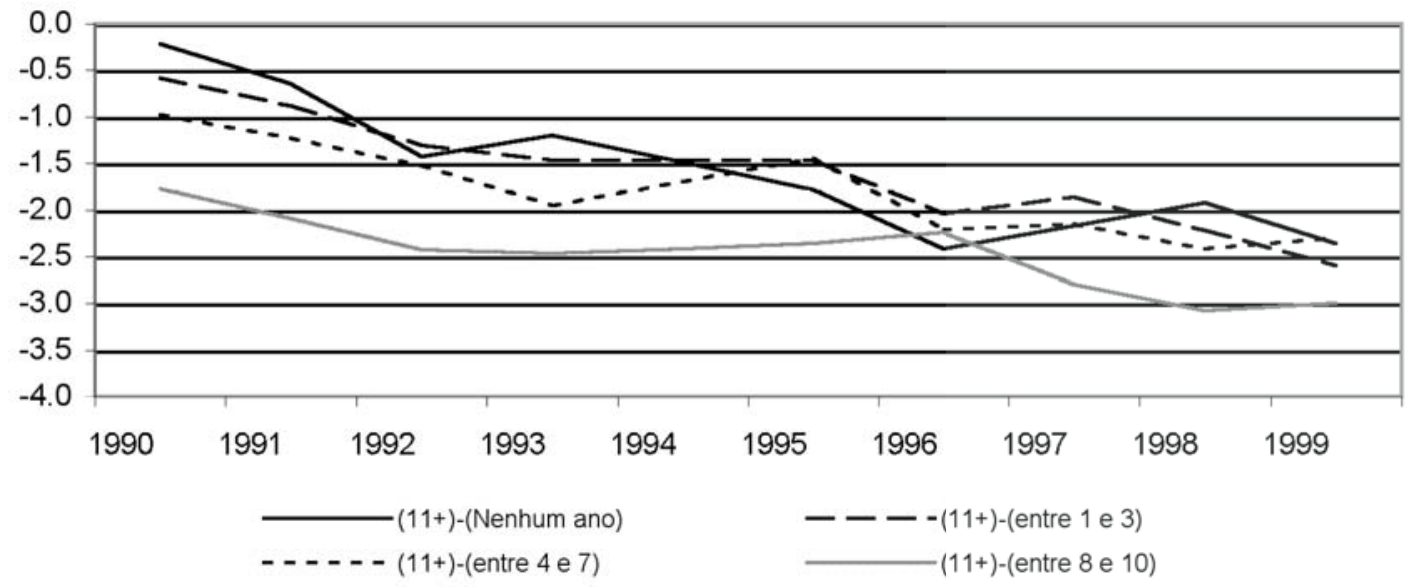

Fonte: Construído com base nos dados das PNADs de 1990 a 1999. Os valores para 1991 e 1994 são interpolações geométricas. A amostra inclui indivíduos entre 25 e 64 anos, residentes nas áreas urbanas.

A tabela 2 mostra a média dos rendimentos do trabalho por escolaridade entre 1990 e 1999 . Nota-se que esses rendimentos caíram para todos os grupos, e que a queda foi menor para os indivíduos sem nenhum ano de escolaridade (3\%). Os grupos com maiores reduções na remuneração média durante todo o período foram aqueles com escolaridade entre 4 e 7 anos e entre 8 e 10 anos (18\% e 17\%, respectivamente). Para os trabalhadores com 11 anos ou mais de estudo ocorreu uma queda de $13 \%$ nos rendimentos reais, um pouco superior à experimentada pelos que possuíam entre 1 e 3 anos de estudo, que foi de $12 \%$. Portanto, os rendimentos relativos dos mais escolarizados aumentaram ou permaneceram praticamente constantes, exceto quando comparados com o grupo sem nenhum ano de educação.

Ao longo da década de noventa, também ocorreram mudanças na participação dos trabalhadores qualificados no total da força de trabalho. Como a tabela 3 mostra, o nível de qualificação da PEA aumentou consideravelmente. Os indivíduos sem nenhum ano de escolaridade, que representavam $12 \%$ do total de trabalhadores em 1990, passaram a representar $9 \%$ desse total em 1999. Os indivíduos com escolaridade entre 1 e 3 anos passaram de $16 \%$ para $12 \%$ da PEA e aqueles com educação entre 4 e 7 anos reduziram a sua participação em 2 pontos percentuais entre 1990 e 1999, de 32\% para 30\%. Os trabalhadores com escolaridade entre 8 e 10 anos aumentaram a participação de 13\% para 16\% da PEA, enquanto os indivíduos com 11 anos ou mais de estudo, que representavam 28\% da PEA em 1990, aumentaram a sua participação para $33 \%$.

A tabela 4 mostra as evoluções das participações de cada grupo educacional no total de gastos com os rendimentos do trabalho principal, que combinam informações sobre mudanças no desemprego, nos rendimentos e na composição da PEA. A tendência é de aumento na parcela correspondente aos trabalhadores com 11 anos de estudo ou mais e de redução na participação dos trabalhadores com menos de 8 anos de escolaridade. Nota-se também, que o grupo mais escolarizado detinha pouco mais da metade do total dos rendimentos do trabalho em 1990, e em 1999 essa parcela aumentou para quase $60 \%$. 
Tabela 2 - Média dos rendimentos do trabalho principal por escolaridade (R\$ de 1999)

\begin{tabular}{lllllll}
\hline Ano & Nenhum ano & $\begin{array}{l}\text { Entre } \\
\text { anos }\end{array}$ & $\begin{array}{l}\text { e } 3 \\
\text { Entre } 4 \\
\text { anos }\end{array}$ & $\begin{array}{l}\text { e } 7 \\
\text { anos } 8 \text { e } 10\end{array}$ & $\begin{array}{l}11 \text { anos ou } \\
\text { mais }\end{array}$ \\
\hline 1990 & 234,62 & 347,67 & 493,98 & 651,29 & 1300,65 \\
1992 & 214,95 & 295,50 & 401,77 & 548,24 & 1022,41 \\
1993 & 200,70 & 291,03 & 395,11 & 538,54 & 1099,89 \\
1995 & 247,51 & 342,60 & 474,49 & 635,63 & 1308,36 \\
1996 & 261,40 & 359,90 & 481,15 & 640,74 & 1284,03 \\
1997 & 249,26 & 350,33 & 455,24 & 630,68 & 1273,33 \\
1998 & 247,73 & 331,11 & 439,38 & 588,60 & 1254,28 \\
1999 & 227,09 & 306,00 & 405,51 & 541,74 & 1127,87 \\
\hline Taxa de Cresci- & $-3,21$ & $-11,99$ & $-17,91$ & $-16,82$ & $-13,28$ \\
mento: 90-99 (\%) & & & & & \\
\hline
\end{tabular}

Fonte: construído com base nos dados das PNADs de 1990 a 1999. A amostra inclui indivíduos entre 25 e 64 anos, residentes nas áreas urbanas, Rendimentos por trabalhador ocupado em Reais de setembro de 1999.

Tabela 3 - Composição da população economicamente ativa por escolaridade (\%)

\begin{tabular}{lllllll}
\hline Ano & Nenhum ano & $\begin{array}{l}\text { Entre } \\
\text { anos }\end{array}$ & $\begin{array}{l}1 \\
\text { e }\end{array}$ & $\begin{array}{l}\text { Entre } \\
\text { anos }\end{array}$ & $\begin{array}{l}\text { e } \\
\text { antre } 8 \text { e } 10\end{array}$ & $\begin{array}{l}11 \text { anos ou } \\
\text { mais }\end{array}$ \\
\hline 1990 & 11,47 & 15,88 & 31,75 & 12,75 & 28,15 \\
1991 & 11,75 & 15,50 & 31,44 & 13,12 & 28,19 \\
1992 & 12,07 & 15,14 & 31,11 & 13,49 & 28,19 \\
1993 & 11,02 & 14,92 & 31,69 & 13,61 & 28,76 \\
1994 & 10,73 & 14,54 & 31,66 & 13,84 & 29,24 \\
1995 & 10,44 & 14,16 & 31,62 & 14,07 & 29,72 \\
1996 & 10,08 & 13,13 & 30,45 & 15,49 & 30,85 \\
1997 & 9,38 & 13,32 & 30,32 & 14,92 & 32,05 \\
1998 & 8,95 & 12,64 & 29,94 & 15,56 & 32,92 \\
1999 & 8,81 & 12,26 & 29,82 & 15,62 & 33,49 \\
\hline Diferença entre & $-2,66$ & $-3,61$ & $-1,93$ & 2,86 & 5,33 \\
1999 e 1990 & & & & & \\
\hline
\end{tabular}

Fonte: construído com base nos dados das PNADs de 1990 a 1999. A amostra inclui indivíduos entre 25 e 64 anos, residentes nas áreas urbanas. 
Tabela 4 - Participação dos grupos educacionais no total de gastos com os rendimentos do trabalho principal (\%)

\begin{tabular}{lllllll}
\hline Ano & Nenhum ano & $\begin{array}{l}\text { Entre } \\
\text { anos }\end{array}$ & $\begin{array}{l}1 \\
\text { e } 3\end{array}$ & $\begin{array}{l}\text { Entre } \\
\text { anos }\end{array}$ & $\begin{array}{l}\text { entre } 8 \text { e } 10 \\
\text { anos }\end{array}$ & $\begin{array}{l}11 \text { anos ou } \\
\text { mais }\end{array}$ \\
\hline 1990 & 3,91 & 8,02 & 22,79 & 12,07 & 53,21 \\
1991 & 4,26 & 8,02 & & 22,61 & 12,66 & 52,46 \\
1992 & 4,65 & 8,02 & 22,41 & 13,26 & 51,66 \\
1993 & 3,81 & 7,48 & 21,57 & 12,63 & 54,50 \\
1994 & 3,74 & 7,19 & 21,46 & 12,68 & 54,93 \\
1995 & 3,68 & 6,90 & 21,35 & 12,73 & 55,34 \\
1996 & 3,68 & 6,60 & 20,48 & 13,87 & 55,36 \\
1997 & 3,29 & 6,57 & 19,43 & 13,25 & 57,46 \\
1998 & 3,17 & 5,98 & 18,79 & 13,08 & 58,99 \\
1999 & 3,12 & 5,86 & 18,87 & 13,20 & 58,94 \\
\hline Variação entre 90 & $-0,79$ & $-2,16$ & $-3,92$ & 1,13 & 5,73 \\
e 99 (\%) & & & & & \\
\hline
\end{tabular}

Fonte: construído com base nos dados das PNADs de 1990 a 1999. A amostra inclui indivíduos entre 25 e 64 anos, residentes nas áreas urbanas.

As evidências apresentadas acima sugerem que o aumento do desemprego relativo dos trabalhadores não-qualificados teria sido ainda maior, caso não tivessem ocorrido mudanças na oferta de qualificação. Para estimar esse efeito, é implementado o seguinte exercício, baseado em Phelps e Zoega (1997). As taxas de desemprego por qualificação são regredidas na taxa de desemprego total, nas ofertas relativas de cada grupo, além de efeitos fixos e tendências temporais específicas dos grupos educacionais, para o período de 1981 a 1999. A partir dos coeficientes estimados são calculadas as taxas de desemprego previstas com a imposição de que as participações de cada grupo educacional no total da força de trabalho fossem as mesmas de 1990.

As taxas de desemprego previstas sem mudanças na composição da oferta são mostradas na tabela 5. De acordo com os resultados, a taxa de desemprego dos trabalhadores sem escolaridade seria de 10,5\% em 1999, o que representa um aumento de 7,79 pontos percentuais na década, 1,31 maior do que o aumento de fato observado. O desemprego também teria sido maior, de acordo com as estimativas, para os indivíduos com escolaridade entre 1 e 3 e entre 4 e 7 anos. A taxa de desemprego prevista em 1999 para os indivíduos com 11 anos ou mais de escolaridade é de 5,13\%, ou seja, uma variação 1,6 ponto percentual menor do que a observada. Esse exercício, portanto, sugere que o crescimento na oferta de trabalho qualificado evitou taxas de desemprego ainda mais elevadas para os não-qualificados.

Resumindo, os fatos estilizados apresentados nessa seção mostram que a estrutura do mercado de trabalho brasileiro passou por intensas modificações durante a década de noventa. 0 desemprego aumentou durante esse período, mas de maneira bastante diferenciada entre os grupos de qualificação. 0 maior aumento do desemprego foi registrado para os trabalhadores não-qualificados, apesar da grande redução da participação desse grupo na força de trabalho. O aumento do desemprego para os trabalhadores semi-qualificados também foi elevado e, além disso, os rendimentos relativos desse grupo diminuíram bastante durante o período. Essas evidências sugerem a presença de deslocamentos na estrutura da demanda por trabalho prejudiciais aos trabalhadores não-qualificados e semi-qualificados. As seções seguintes procuram desenvolver a análise dessa questão. 
Tabela 5 - Taxa de desemprego prevista sem mudanças na composição da PEA(\%)

\begin{tabular}{|c|c|c|c|c|c|}
\hline Ano & Nenhum ano & $\begin{array}{llll}\text { Entre } & 1 & \text { e } & 3 \\
\text { anos } & & & \end{array}$ & $\begin{array}{llll}\text { Entre } & 4 & \text { e } & 7 \\
\text { anos } & & & \end{array}$ & $\begin{array}{l}\text { Entre } 8 \text { e } 10 \\
\text { anos }\end{array}$ & $\begin{array}{l}11 \text { anos ou } \\
\text { mais }\end{array}$ \\
\hline 1990 & 2,71 & 3,00 & 3,30 & 3,61 & 2,42 \\
\hline 1991 & 3,92 & 4,30 & 4,62 & 4,97 & 3,27 \\
\hline 1992 & 5,67 & 6,15 & 6,49 & 6,83 & 4,43 \\
\hline 1993 & 5,40 & 5,80 & 5,99 & 6,17 & 3,94 \\
\hline 1994 & 5,51 & 5,87 & 5,93 & 6,00 & 3,77 \\
\hline 1995 & 5,63 & 5,95 & 5,88 & 5,82 & 3,60 \\
\hline 1996 & 6,79 & 7,10 & 6,87 & 6,67 & 4,05 \\
\hline 1997 & 7,87 & 8,15 & 7,73 & 7,35 & 4,40 \\
\hline 1998 & 9,09 & 9,33 & 8,66 & 8,07 & 4,75 \\
\hline 1999 & 10,50 & 10,68 & 9,71 & 8,86 & 5,13 \\
\hline $\begin{array}{l}\text { (a) Diferença en- } \\
\text { tre } 99 \text { e } 90 \text { (pre- } \\
\text { vista) }\end{array}$ & 7,79 & 7,68 & 6,41 & 5,25 & 2,72 \\
\hline $\begin{array}{l}\text { (b) Diferença en- } \\
\text { tre } 99 \text { e } 90 \text { (obser- } \\
\text { vada) }\end{array}$ & 6,48 & 6,35 & 5,65 & 5,56 & 4,34 \\
\hline $\begin{array}{l}\text { Linha (a) - Linha } \\
\text { (b) }\end{array}$ & 1,31 & 1,33 & 0,76 & $-0,32$ & $-1,62$ \\
\hline
\end{tabular}

Nota: As taxas de desemprego previstas são obtidas da seguinte maneira. Usando dados de 1981 a 1999 é estimada a regressão por mínimos quadrados: $u_{i t}=\alpha_{i}+\beta_{0} T_{i}+\beta_{1} l_{i t}+\beta_{2} u_{t}+\varepsilon_{i t}$, onde $u_{i t}$ é a taxa de desemprego do grupo i no período t, $\alpha_{i}$ representa o efeito fixo de i, $T_{i}$ é uma tendência temporal específica de i, $l_{i t}$ é a participação do grupo i na PEA, no período t e $u_{t}$ é a taxa de desemprego total em t. Fixando as participações de cada grupo na PEA $\left(l_{i t}\right)$ nos seus valores de 1990 , são calculadas as taxas de desemprego previstas para cada grupo com base nos coeficientes estimados.

\section{O MODELO}

Para analisar os efeitos de choques agregados e relativos sobre o desemprego é utilizada uma extensão do modelo de Nickell e Bell (1996), com três tipos de trabalhadores: qualificados, semi-qualificados e não-qualificados.

O modelo supõe que o produto $(\mathrm{Y})$ da economia é produzido de acordo com uma função de produção do tipo CES, homogênea de grau 1 nos três tipos de trabalho, representados por $\left(N_{i}\right)$. Indexando os trabalhadores qualificados por (q), os semi-qualificados por (m) e os não-qualificados por (n), temos:

$$
Y^{\rho}=\xi\left(\alpha_{q} N_{q}^{\rho}+\alpha_{m} N_{m}^{\rho}+\alpha_{n} N_{n}^{\rho}\right) \quad\left(1-\rho=1 / \sigma, \alpha_{q}+\alpha_{m}+\alpha_{n}=1 \text { e } \rho \leq 1\right)
$$

onde:

$\sigma$ elasticidade-substituição entre trabalhadores com diferentes níveis de qualificação.

$\alpha_{i}$ parâmetro de produtividade do trabalhador com qualificação i.

$N_{i}$ nível de emprego do trabalhador com qualificação i.

$\xi$ índice de produtividade agregada.

Na equação (1), supõe-se que a elasticidade-substituição $(\sigma)$ é a mesma entre os diferentes tipos de trabalhadores. Essa restrição evidentemente não é satisfatória, pois deve-se esperar que para cada dois 
tipos de trabalhadores comparados os valores da elasticidade-substituição sejam diferentes. Infelizmente, uma especificação com essas características não permitiria que os parâmetros da elasticidadesubstituição fossem estimados. Outras alternativas implicariam em adotar outros tipos de hipóteses restritivas, como as utilizadas por Fernandes e Menezes-Filho (2002) ${ }^{2}$.

Supondo que o mercado de produto seja competitivo, e normalizando o preço do produto para um, a demanda por trabalho do tipo i é dada por:

$$
w_{i}=\alpha_{i} \xi\left(N_{i} / Y\right)^{-1 / \sigma}=\alpha_{i}\left(\left(1-u_{i}\right)\left(L_{i} / L\right)\right)^{-1 / \sigma} X \quad(i=q, m, n)
$$

onde:

$w_{i}$ salário real pago pela firma ao trabalhador com qualificação i.

$L_{i}$ força de trabalho com qualificação i.

$L$ força de trabalho total.

$u_{i}$ taxa de desemprego do grupo com qualificação i.

$X=\xi(Y / L)^{1 / \sigma}$ é uma medida de produtividade agregada.

Suponha que os salários de cada grupo de qualificação sejam determinados por uma curva de salário:

$$
w_{i}=\gamma_{i} f\left(u_{i}\right) X \quad(i=q, m, n)
$$

onde:

$$
\frac{\partial f\left(u_{i}\right)}{\partial u_{i}}<0 .
$$

$\gamma_{i}=$ pressão salarial dos trabalhadores com qualificação i.

A curva de salário é caracterizada por uma relação negativa entre salários e taxa de desemprego. De acordo com Blanchflower et alii (1994) e Blanchflower e Oswald (1995), há uma tendência para que os salários em mercados de trabalho com desemprego elevado sejam menores do que em mercados com desemprego baixo, mantendo tudo mais constante. O argumento teórico por trás dessa relação pode ser encontrado nos modelos de salário-eficiência e de barganha salarial. ${ }^{3}$ Blanchflower et alii (1994) e Blanchflower e Oswald (1995) mostram que estimativas da curva de salário para vários países confirmam a relação negativa prevista pela teoria.

A economia está sujeita a choques agregados e relativos. Choques agregados alteram as taxas de desemprego dos três grupos de qualificação na mesma direção. Esses choques podem ser representados

\footnotetext{
${ }^{2}$ Fernandes e Menezes-Filho (2002) dividem as tarefas desenvolvidas pelos trabalhadores entre simples e complexas. As tarefas simples podem ser desempenhadas por não-qualificados e semi-qualificados e as tarefas complexas podem ser desempenhadas por qualificados e semi-qualificados. No entanto, uma série de restrições são adotadas nessa especificação. Em primeiro lugar, as tarefas simples e complexas são determinadas por uma função Cobb-Douglas, o que significa que a elasticidade-substituição entre tarefas simples e complexas deve tender para um. Como as participações das tarefas no produto total são constantes ao longo do tempo, não é permitida a situação em que o progresso tecnológico torna os trabalhadores qualificados mais eficientes em tarefas antes realizadas por trabalhadores não-qualificados. Além disso, a especificação exclui a possibilidade dos trabalhadores qualificados desempenharem as mesmas tarefas que os semi-qualificados e os não-qualificados.

${ }^{3}$ No modelo de barganha, taxas de desemprego mais elevadas fazem com que indivíduos que perdem os seus empregos tenham mais dificuldades para conseguir um novo trabalho. Portanto, o aumento do desemprego leva a redução no salário alternativo, e conseqüentemente a menores salários.

No modelo de salário-eficiência, versão Shapiro e Stiglitz (1984), a taxa de desemprego influencia o salário que a firma deve pagar para incentivar o esforço dos trabalhadores. Quando a taxa de desemprego é baixa, os trabalhadores podem encontrar um outro emprego com facilidade e exigem uma remuneração alta para se esforçarem, estabelecendo uma relação negativa entre desemprego e salário.
} 
tanto por variações semelhantes na pressão salarial de todos os grupos $\left(\gamma_{i}\right)$, quanto por mudanças na produtividade total da economia $(\xi)$, que afetam a demanda por trabalho dos três grupos. Os efeitos dos choques agregados sobre as taxas de desemprego de cada tipo dependem da flexibilidade salarial. Com uma alta elasticidade da curva de salário, por exemplo, choques agregados têm impactos relativamente mais acentuados sobre os salários do que sobre o desemprego.

Definindo um choque agregado adverso por variações nos parâmetros de pressão salarial que não alteram as relações entre os grupos, $\frac{\gamma_{n}}{\gamma_{q}}, \frac{\gamma_{n}}{\gamma_{m}}, \frac{\gamma_{m}}{\gamma_{q}}$, podemos caracterizar um choque desse tipo por: $d \ln \gamma_{q}=d \ln \gamma_{m}=d \ln \gamma_{n}=d \ln \gamma \geq 0$.

Choques relativos são representados por mudanças nas produtividades dos grupos de qualificação $\left(d \alpha_{i}\right)$. Como resultado do progresso tecnológico, devemos esperar um aumento na produtividade dos trabalhadores qualificados e uma redução na produtividade dos não-qualificados. Choques relativos são definidos de maneira que, mantendo o emprego de cada grupo constante, as variações nos parâmetros de produtividade não alteram o produto total da economia:

$$
r_{q} d \alpha_{q}+r_{m} d \alpha_{m}+r_{n} d \alpha_{n}=0
$$

onde $r_{i}=\left(\frac{N_{i}}{N}\right)^{\rho}$.

Primeiramente, é descrito de que forma um choque agregado apresenta efeitos diferenciados sobre as taxas de desemprego dos trabalhadores qualificados, semi-qualificados e não-qualificados. Da equação (3), podemos obter as seguintes relações entre os salários relativos ${ }^{4}$ :

$$
\begin{aligned}
& \frac{w_{n}}{w_{q}} \frac{f\left(u_{q}\right)}{f\left(u_{n}\right)}=\frac{\gamma_{n}}{\gamma_{q}}=\text { constante } \\
& \frac{w_{n}}{w_{m}} \frac{f\left(u_{m}\right)}{f\left(u_{n}\right)}=\frac{\gamma_{n}}{\gamma_{m}}=\text { constante }
\end{aligned}
$$

Substituindo $w_{i}$ da equação (2) nas equações acima e mantendo as participações de cada grupo na força de trabalho constantes, podemos calcular a variação no desemprego de um grupo em relação ao outro em resposta a um choque agregado:

$$
\begin{array}{r}
\frac{d u_{m}}{d u_{q}}=\frac{\left[\frac{\eta_{q}}{u_{q}}-\frac{1}{\sigma\left(1-u_{q}\right)}\right]}{\left[\frac{\eta_{m}}{u_{m}}-\frac{1}{\sigma\left(1-u_{m}\right)}\right]} \\
\frac{d u_{n}}{d u_{q}}=\frac{\left[\frac{\eta_{q}}{u_{q}}-\frac{1}{\sigma\left(1-u_{q}\right)}\right]}{\left[\frac{\eta_{n}}{u_{n}}-\frac{1}{\sigma\left(1-u_{n}\right)}\right]}
\end{array}
$$

Onde: $\eta\left(u_{i}\right)=\frac{\partial f\left(u_{i}\right)}{\partial u_{i}} \frac{u_{i}}{f\left(u_{i}\right)} \dot{\eta}$ é a elasticidade do salário com relação ao desemprego derivada da curva de salário.

Choques relativos são representados por variações nos parâmetros de produtividade $\left(d \alpha_{i}\right)$ que satisfazem a equação (4). Igualando os salários para cada tipo de trabalhador nas equações (2) e (3) e considerando as mudanças na composição da força de trabalho e nos parâmetros de produtividade, temos os seguintes resultados:

\footnotetext{
${ }^{4}$ A relação entre qualificados e semi-qualificados pode ser obtida simplesmente dividindo a equação (5a) pela equação (5b).
} 


$$
\begin{array}{r}
\phi\left(u_{q}\right) d u_{q}=-\frac{d \alpha_{q}}{\alpha_{q}}+d \ln \gamma+\frac{1}{\sigma} d \ln \left(\frac{L_{q}}{L}\right) \\
\phi\left(u_{m}\right) d u_{m}=-\frac{d \alpha_{m}}{\alpha_{m}}+d \ln \gamma+\frac{1}{\sigma} d \ln \left(\frac{L_{m}}{L}\right) \\
\phi\left(u_{n}\right) d u_{n}=-\frac{d \alpha_{n}}{\alpha_{n}}+d \ln \gamma+\frac{1}{\sigma} d \ln \left(\frac{L_{n}}{L}\right)
\end{array}
$$

Onde: $\phi(u)=[1 / \sigma(1-u)]+\eta(u) / u$.

Para resolver o modelo, precisamos identificar os três parâmetros de produtividade $\left(\alpha_{i}\right)$ e as suas variações $\left(d \alpha_{i}\right)$. Pelas equações de demanda por trabalho, os salários relativos são dados por: $\frac{w_{q}}{w_{n}}=$ $\left(\frac{\alpha_{q}}{\alpha_{n}}\right)\left(\frac{N_{q}}{N-m}\right)^{-\frac{1}{\sigma}}$ e $\frac{w_{m}}{w_{n}}=\left(\frac{\alpha_{m}}{\alpha_{n}}\right)\left(\frac{N_{m}}{N_{n}}\right)^{-\frac{1}{\sigma}}$. Usando essas duas equações e a restrição $\alpha_{q}+\alpha_{m}+\alpha_{n}=$ 1, que é simplesmente uma normalização, os parâmetros de produtividade de cada tipo de trabalhador podem ser identificados.

Podemos eliminar $d \ln \gamma$ substituindo a equação (7a) na equação (7b) e a equação (7b) na equação(7c):

$$
\begin{gathered}
\frac{d \alpha_{q}}{\alpha_{q}}-\frac{d \alpha_{m}}{\alpha_{m}}=\left[\phi\left(u_{m}\right) d u_{m}-\phi\left(u_{q}\right) d u_{q}+\frac{1}{\sigma} d \ln \left(\frac{L_{q}}{L}\right)-\frac{1}{\sigma} d \ln \left(\frac{L_{m}}{L}\right)\right] \\
\frac{d \alpha_{m}}{\alpha_{m}}-\frac{d \alpha_{n}}{\alpha_{n}}=\left[\phi\left(u_{n}\right) d u_{n}-\phi\left(u_{m}\right) d u_{m}+\frac{1}{\sigma} d \ln \left(\frac{L_{m}}{L}\right)-\frac{1}{\sigma} d \ln \left(\frac{L_{n}}{L}\right)\right]
\end{gathered}
$$

Substituindo os valores de $\alpha_{i}$ nas equações (8a) e (8b), o próximo passo agora é obter as variações nos parâmetros de produtividade de cada um dos grupos de trabalhadores. Isso é feito através do sistema formado pelas equações (4), (8a) e (8b).

Com as variações nas produtividades de cada tipo, podemos calcular as mudanças no desemprego provocadas por alterações na demanda relativa. Fazendo $d \ln \gamma=0$, e substituindo $d \alpha_{i}$ nas equações (7a), (7b) e (7c), temos as variações no desemprego provocadas por choques relativos de produtividade para os trabalhadores não-qualificados $\left(d u_{n}^{*}\right)$, semi-qualificados $\left(d u_{m}^{*}\right)$ e para os trabalhadores qualificados $\left(d u_{q}^{*}\right)$. Podemos, então, obter $d u_{i}^{*}$ imputando os valores dos parâmetros nas equações abaixo.

$$
\begin{array}{r}
\phi\left(u_{q}\right) d u_{q}^{*}=\frac{1}{\sigma} d \ln \left(\frac{L_{q}}{L}\right)-\frac{d \alpha_{q}}{\alpha_{q}} \\
\phi\left(u_{m}\right) d u_{m}^{*}=\frac{1}{\sigma} d \ln \left(\frac{L_{m}}{L}\right)-\frac{d \alpha_{m}}{\alpha_{m}} \\
\phi\left(u_{n}\right) d u_{n}^{*}=\frac{1}{\sigma} d \ln \left(\frac{L_{n}}{L}\right)-\frac{d \alpha_{n}}{\alpha_{n}}
\end{array}
$$

\section{RESULTADOS EMPÍRICOS}

Para calcular os efeitos de choques agregados e relativos sobre o desemprego são necessários os parâmetros das curvas de salário $\left(\eta_{i}\right)$ e a elasticidade-substituição entre trabalhadores de diferentes níveis de qualificação $(\sigma)$. Essa seção apresenta os resultados estimados para esses parâmetros. Na subseção 5.1 são estimadas as curvas de salário por qualificação e na subseção 5.2 são mostrados os resultados para a elasticidade-substituição. 


\subsection{As curvas de salário}

As curvas de salário são estimadas separadamente para os trabalhadores qualificados, semi-qualificados e não-qualificados usando dados da PNAD para o período de 1990 a 1999 . Seguindo o procedimento padrão na literatura sobre curva de salário, as medidas de rendimentos são construídas usando controles para as características individuais. Para isso, os rendimentos em log de cada indivíduo em cada ano são regredidos nas seguintes variáveis: gênero, idade, idade ao quadrado, escolaridade (5 grupos), região de residência, setor de atividade (9 setores), posição no domicílio (chefe, cônjuge e outros) e posição na ocupação (com carteira, sem carteira, conta-própria, empregador, funcionário público e militar). A partir dessas estimativas são calculados os valores previstos dos rendimentos reais para cada indivíduo e calculadas as médias por unidade da federação para cada um dos três grupos de qualificação. Em cada unidade da federação também são calculadas as taxas de desemprego por nível de qualificação. Com esses valores as curvas de salário são estimadas em primeira diferença de acordo com a seguinte especificação:

$$
\Delta \ln \left(w_{r t}\right)=\sum_{t=1}^{T} \gamma_{t} T_{t}+\eta_{\Delta} \ln \left(u_{r t}\right)+\varepsilon_{r t}
$$

Onde:

$\Delta \ln \left(w_{r t}\right)$ variação do $\log$ do rendimento médio real na unidade da federação $r$ no período $t$.

$D T_{t}$ variável dummy de tempo.

$\Delta \ln \left(u_{r t}\right)$ variação do log da taxa de desemprego na unidade da federação $r$ no período $t$.

As regressões são ponderadas pelo número relativo de trabalhadores com a qualificação considerada em cada unidade da federação, e dummies de tempo são incluídas para captar os efeitos agregados do mercado de trabalho sobre os mercados regionais. Como a taxa de desemprego deve ser endógena em relação aos rendimentos, as curvas de salário são estimadas pelo método de variáveis instrumentais, onde a taxa de desemprego defasada em um período é utilizada como instrumento.

As relações entre os rendimentos e a taxa de desemprego também são estimadas com as variáveis em nível e a inclusão de efeitos fixos por unidade da federação para captar as diferenças regionais nos salários. Como ressaltam Baltagi e Blien (1998) e Baltagi et alii (2000), os estimadores dos modelos em primeira diferença e com efeitos fixos são afetados de forma diferenciada pelo mesmo instrumento. A consistência do estimador com efeitos fixos é testada através do teste de Hausman proposto por Keane e Runkle (1992) ${ }^{5}$.

De acordo com os resultados, apresentados na tabela 6, a curva de salário dos trabalhadores qualificados apresenta a menor inclinação $(-0,013)$, o que significa que os rendimentos desse grupo são menos sensíveis a variações na taxa de desemprego. As elasticidades estimadas para os trabalhadores nãoqualificados e os semi-qualificados são de $-0,051$ e $-0,045$, respectivamente. Portanto, os rendimentos nesses dois grupos se mostraram mais flexíveis a mudanças no desemprego.

Barros e Mendonça (1997), com dados da PME (Pesquisa Mensal de Emprego), calculada pelo IBGE, estimam curvas de salário para o Brasil entre 1983 e 1996. Apesar das diferenças na base de dados e na metodologia, esses autores também encontram uma elasticidade mais baixa para os trabalhadores qualificados. Em geral, as evidências encontradas na literatura internacional também mostram que

\footnotetext{
${ }^{5} \mathrm{O}$ teste tem distribuição $\chi^{2}$ com os graus de liberdade dados pelo número de coeficientes comparados nos dois métodos de estimação. A rejeição da hipótese nula indica que o estimador com efeitos fixos não é consistente para o instrumento escolhido.
} 
Tabela 6 - Curvas de salário por nível de qualificação

\begin{tabular}{llllll}
\hline & $\begin{array}{l}\text { Log do } \\
\text { desemprego }\end{array}$ & Obs & $R^{2}$ & $\chi^{2}(7)$ & $\begin{array}{l}\text { Dummies de } \\
\text { Tempo }\end{array}$ \\
\hline $\begin{array}{l}\text { Não- } \\
\text { qualificados }\end{array}$ & $-0,051(0,038)$ & $\begin{array}{l}168 \\
(1990-1999)\end{array}$ & 0,84 & 21,64 & Sim \\
$\begin{array}{l}\text { Semi- } \\
\text { qualificados } \\
\text { Qualificados }\end{array}$ & $-0,045(0,035)$ & $\begin{array}{l}168 \\
(1990-1999) \\
164\end{array}$ & 0,87 & 37,74 & Sim \\
& $-0,013(0,025)$ & 0,91 & 19,64 & Sim \\
\hline
\end{tabular}

Variável dependente: $\log$ dos rendimentos do trabalho principal por indivíduo. Amapá e Roraima foram excluídos por causa do pequeno número de observações nessas Unidades da Federação. Observações referentes a Tocantins foram agregadas a Goiás. Todas as regressões usam variáveis dummy de tempo. Cada observação é ponderada pela sua participação relativa na PEA no ano. Os erros-padrão robustos são mostrados entre parênteses. A estatística $\chi^{2}(7)$ é referente ao teste de Hausman para os modelos com efeitos fixos e em primeira diferença.

os salários dos trabalhadores menos qualificados apresentam uma flexibilidade maior em relação às variações no desemprego do que os salários dos mais qualificados ${ }^{6}$.

\subsection{A elasticidade-substituição}

A partir da equação (2), pode ser obtida a demanda por trabalhadores qualificados em relação aos não-qualificados:

$$
\ln \frac{N_{q}}{N_{n}}=\sigma\left(\ln \frac{\alpha_{q}}{\alpha_{n}}-\ln \frac{w_{q}}{w_{n}}\right)
$$

Usando dados da PNAD para o emprego e a média dos rendimentos em 31 setores da economia durante o período de 1990 a 1999, pode-se estimar o parâmetro de elasticidade-substituição. O termo $\ln \frac{\alpha_{q}}{\alpha_{n}}$, a produtividade relativa entre os dois tipos de trabalhadores, é representado por dummies de tempo.

$$
\ln \left(\frac{N_{s q t}}{N_{\text {snt }}}\right)=\alpha+\sum_{t=1}^{T} \gamma_{t} D T_{t}+\sigma \ln \left(\frac{w_{s q t}}{w_{\text {snt }}}\right)+\varepsilon_{s t}
$$

Onde:

$\ln \left(\frac{N_{s q t}}{N_{s q t}}\right)$ logaritmo da razão entre os níveis de emprego de qualificados e não-qualificados no setor $s$, no período $t$.

$\ln \left(\frac{w_{s q t}}{w_{s q t}}\right)$ logaritmo da razão entre os rendimentos médios de qualificados e não-qualificados no setor $s$, no período $t$.

$D T_{t}$ variáveis dummy de tempo.

\footnotetext{
${ }^{6}$ Blanchflower et alii (1994) encontram esse resultado para os Estados Unidos, Canadá e Reino Unido. Na Austrália, porém, a elasticidade estimada por esses autores é superior para os qualificados. Card (1995), usando dados para os Estados Unidos, obtém uma elasticidade maior para os trabalhadores semi-qualificados $(-0,09)$, seguidos pelos não-qualificados $(-0,04)$ e os qualificados $(-0,01)$. Outros artigos que estimam elasticidades mais baixas da curva de salário para os trabalhadores qualificados são: Gregg e Manning (1997) para o Reino Unido, Baltagi e Blien (1998) para a Alemanha e Berg e Contreras (2002) para o Chile. Nickell e Bell (1995) encontram uma elasticidade ligeiramente maior, em valor absoluto, para os trabalhadores qualificados $(-0,062)$ do que para os não-qualificados $(-0,054)$ no Reino Unido.
} 
$\alpha$ constante.

A equação (12) é estimada usando outras especificações que consistem na inclusão de tendências setoriais e de efeitos fixos para os setores. Como a razão entre os rendimentos deve ser endógena em relação ao emprego relativo, as duas primeiras defasagens do logaritmo da razão entre os rendimentos dos qualificados e dos não-qualificados são usadas como instrumento. Para estimar a elasticidadesubstituição na equação (12) os trabalhadores semi-qualificados são transformados em equivalentes não-qualificados e qualificados através do procedimento sugerido por Katz e Murphy (1992). O método consiste em representar os semi-qualificados como uma combinação linear dos outros dois grupos, através das relações entre os rendimentos médios. ${ }^{7}$

Os resultados estimados para a elasticidade-substituição são mostrados na tabela (7). Na coluna (1), em que apenas dummies de tempo são usadas como controles, o valor estimado para $\sigma$ é de 2,57 . Na coluna (2), são incluídas tendências diferenciadas entre os setores. Nesse caso, a elasticidade-substituição encontrada é de 1,41. Acrescentando variáveis para captar as diferenças nos níveis de emprego relativo entre os setores, o resultado é $\sigma=1,32$.

Tabela 7 - Elasticidade-substituição entre qualificados e não-qualificados

\begin{tabular}{|c|c|c|c|}
\hline & (1) & (2) & (3) \\
\hline $\ln (w q / w n)$ & $-2,572(0,2)$ & $-1,412(0,64)$ & $-1,32(0,78)$ \\
\hline Tendência por setor ${ }^{a}$ & - & Sim & Sim \\
\hline Controles por setor ${ }^{b}$ & - & - & Sim \\
\hline Observações & 185 & 185 & 185 \\
\hline Período & $90-99$ & $90-99$ & $90-99$ \\
\hline$R^{2}$ & 0,41 & 0,74 & 0,75 \\
\hline
\end{tabular}

As regressões são implementadas com dados da PNAD para o período 90-99. Os erros-padrão robustos são mostrados entre parênteses. Todas as regressões usam variáveis dummy de tempo. Os números relativos de empregados em cada setor são usados como ponderadores. As duas primeiras defasagens do logaritmo da razão entre os salários de qualificados e não-qualificados são utilizadas como instrumentos. ${ }^{a}$ São utilizadas tendências temporais específicas dos setores agregados (8 grupos de setores). ${ }^{b}$ São utilizadas variáveis de controle para os setores agregados (8 grupos de setores).

Katz e Murphy (1992) encontram uma elasticidade de 1,41 para os Estados Unidos, entre 1963 e 1987. Manacorda e Petrongolo encontram um coeficiente próximo de um para seis países da OCDE (França, Alemanha, Itália, Holanda, Reino Unido e EUA), 1,059, o que implica em uma função de produção agregada Cobb-Douglas. Estudos reportados por Hammermesh (1993), que utilizam uma função de produção do tipo CES, encontram elasticidades de 4,1 e 2,5 para os Estados Unidos. Usando resultados de estudos recentes, Johnson (1997) conclui que o parâmetro $\sigma$ deve estar em torno de 1,5 nos Estados Unidos. ${ }^{8}$

\footnotetext{
${ }^{7}$ Para implementar o método proposto por Katz e Murphy (1992) os trabalhadores semi-qualificados (divididos em trabalhadores com escolaridade entre 4 e 7 anos e entre 8 e 10 anos) têm os seus rendimentos médios regredidos nos rendimentos médios dos qualificados e dos não-qualificados. Assim, são obtidos os pesos para representar os rendimentos de cada um dos conjuntos de semi-qualificados como uma combinação linear dos outros dois tipos de trabalhadores. Os resultados estimados são os seguintes: $w_{4-7}=0,114 w_{q}+0,921 w_{n}$ e $w_{8-10}=0,273 w_{q}+0,657 w_{n}$, onde $w_{4-7}$ e $w_{8-10}$ são os rendimentos médios dos trabalhadores com escolaridade entre 4 e 7 e entre 8 e 10 anos, respectivamente e $w_{q}$ e $w_{n}$ são os rendimentos dos qualificados e não-qualificados, respectivamente. Através desses pesos, os trabalhadores semi-qualificados são classificados como equivalentes qualificados e não-qualificados. Assim, $N_{s q t}$ é a soma dos empregados qualificados, com 11 anos de estudos ou mais, com os semi-qualificados considerados equivalentes aos qualificados.

${ }^{8}$ Os valores do parâmetro de elasticidade-substituição têm as seguintes implicações para o formato da função de produção:
} 


\section{OS IMPACTOS DE CHOQUES AGREGADOS E RELATIVOS SOBRE O DESEMPREGO}

Com os valores estimados na seção anterior para as curvas de salário e a elasticidade-substituição, além de outras variáveis observadas diretamente da PNAD, podem ser calculadas as contribuições dos choques agregados e relativos para o desemprego. Na subseção 5.1 são apresentados os resultados para os choques agregados, usando as equações (6a) e (6b), e na subseção 5.2 são mostrados os efeitos de choques relativos, obtidos a partir das equações (9a), (9b) e (9c). Em ambos os casos os resultado são calculados com os dois valores extremos estimados para a elasticidade-substituição: $\sigma=1,31$ e $\sigma=2,57 .^{9}$

\subsection{Choques agregados}

De acordo com os resultados apresentados na tabela 8, choques agregados adversos provocam aumentos da taxa de desemprego muito maiores para os qualificados do que para os demais grupos. Os trabalhadores semi-qualificados e os não-qualificados parecem se ajustar mais a choques desse tipo reduzindo os salários, enquanto a maior rigidez salarial dos qualificados faz com que os efeitos sobre o desemprego sejam mais intensos. O mesmo choque agregado que provoca um aumento na taxa de desemprego dos trabalhadores qualificados de 1 ponto percentual, aumenta o desemprego dos semiqualificados entre 0,55 e 0,62 pontos percentuais. Comparando os qualificados com os não-qualificados, para cada ponto percentual de aumento na taxa de desemprego dos primeiros, ocorre um aumento entre 0,49 e 0,57 pontos percentuais para o segundo grupo. ${ }^{10}$

Tabela 8 - Efeitos de choques agregados sobre a variação do desemprego por nível de qualificação1990:1999

\begin{tabular}{llll}
\hline & $\begin{array}{l}\sigma: \text { elasticidade- subs- } \\
\text { tituição }\end{array}$ & $d u_{m} / d u_{q}$ & $d u_{n} / d u_{q}$ \\
\hline$(1)$ & 1,32 & 0,62 & 0,57 \\
$(2)$ & 2,57 & 0,55 & 0,49 \\
\hline
\end{tabular}

Nota: os efeitos dos choques agregados são calculados imputando os valores dos parâmetros nas equações (6a) e (6b).

A tabela 10 do apêndice B mostra os resultados encontrados usando as curvas de salário obtidas com os rendimentos por hora, e as evidências são bastante semelhantes as apresentadas na tabela 8 . No apêndice $C$, são reportados os resultados usando dados da PME. Nesse caso, para cada aumento em 1 ponto percentual da taxa de desemprego dos qualificados, choques agregados provocam aumentos inferiores a meio ponto percentual para os não-qualificados e entre 0,25 e 0,29 para os semi-qualificados.

De acordo com as evidências empíricas encontradas, choques agregados teriam contribuído para o aumento no desemprego relativo dos qualificados. Esse efeito vai no sentido contrário às variações observadas nas taxas de desemprego por nível de qualificação, o que ressalta a importância dos choques relativos.

valores muito elevados de $\sigma$ significam que os insumos são altamente substitutos. Quando $\sigma$ tende para um a função de produção é do tipo Cobb-Douglas e quando $\sigma$ tende para zero a função de produção é do tipo Leontieff.

${ }^{9}$ Os resultados também foram calculados para $\sigma=1,41$, e se mostraram bastante semelhantes aos encontrados com $\sigma=1,32$.

${ }^{10}$ Nickell e Bell (1995) obtêm 0,83\% para a comparação entre qualificados e não-qualificados na OCDE. 


\subsection{Choques relativos}

A primeira coluna da tabela 9 mostra as variações estimadas nos parâmetros de produtividade, seguindo os passos descritos na seção 4. De acordo com os resultados, ocorreu um aumento na produtividade dos qualificados de $7 \%$ a $11 \%$ durante a década de noventa. Os níveis de produtividade dos semi-qualificados, e principalmente dos não-qualificados, por outro lado, parecem ter diminuído bastante em relação aos qualificados. Para os semi-qualificados foi estimada uma queda entre $4 \%$ e $6 \%$, enquanto para os não-qualificados a redução do parâmetro de produtividade foi estimada entre $20 \%$ e $33 \%$.

Tabela 9 - Efeitos de choques relativos sobre o desemprego por nível de qualificação - 1990:1999

\begin{tabular}{|c|c|c|c|}
\hline & (1) & (2) & 3) \\
\hline & $\begin{array}{l}\text { Variações dos parâme- } \\
\text { tros de produtividade } \\
(\%)\end{array}$ & $\begin{array}{l}\text { Variações no desem- } \\
\text { prego resultantes de } \\
\text { mudanças relativas } \\
\text { na produtividade } \\
\text { e na composição } \\
\text { da PEA (em pontos } \\
\text { percentuais) }\end{array}$ & $\begin{array}{l}\text { Participação dos cho- } \\
\text { ques relativos na vari- } \\
\text { ação da taxa de desem- } \\
\text { prego (\%) }\end{array}$ \\
\hline \multicolumn{4}{|c|}{ Não-qualificados } \\
\hline$\sigma=1,32$ & $-32,6$ & 4,9 & 76,8 \\
\hline$\sigma=2,57$ & $-19,9$ & 4,4 & 68,5 \\
\hline \multicolumn{4}{|c|}{ Semi-qualificados } \\
\hline$\sigma=1,32$ & $-6,2$ & 3,8 & 66,8 \\
\hline$\sigma=2,57$ & $-4,2$ & 2,9 & 52,7 \\
\hline \multicolumn{4}{|c|}{ Qualificados } \\
\hline$\sigma=1,32$ & 11,3 & 1,4 & 32,1 \\
\hline$\sigma=2,57$ & 7,2 & $-0,5$ & $-10,6$ \\
\hline \multicolumn{4}{|l|}{ Total } \\
\hline$\sigma=1,32$ & - & 3,2 & 60,1 \\
\hline$\sigma=2,57$ & - & 2,1 & 39,7 \\
\hline
\end{tabular}

Nota: os efeitos dos choques relativos são calculados imputando os valores dos parâmetros nas equações (9a), (9b) e (9c).

Na segunda coluna da tabela 9, são apresentados os efeitos de variações na produtividade relativa e na composição da oferta sobre o desemprego por qualificação, referentes a $d u_{i}^{*}$ nas equações (9a), (9b) e (9c). Os resultados mostram que esses choques relativos somados provocaram aumentos substanciais na taxa de desemprego dos trabalhadores não-qualificados, entre 4,4 e 4,9 pontos percentuais, dependendo do valor de $\sigma$. Esses choques também afetaram negativamente os semi-qualificados, aumentando a taxa de desemprego desse grupo entre 2,9 e 3,8 pontos percentuais. Com relação aos trabalhadores qualificados, enquanto o aumento da produtividade contribuiu para a redução da taxa de desemprego, a maior participação desses trabalhadores na PEA teve efeito contrário. O saldo final, de acordo com o modelo, indica desde uma pequena redução de 0,4 pontos percentuais a um aumento de 1,3 ponto percentual na taxa de desemprego desse grupo, dependendo do valor da elasticidade-substituição. Notase também que com $\sigma=1,32$ as variações nas taxas de desemprego são maiores para todos os grupos do que com $\sigma=2,57$. Isso significa que uma maior elasticidade-substituição entre trabalhadores permite que a economia se ajuste melhor a mudanças estruturais, levando a menores variações nas taxas de 
desemprego de todos os grupos.

Avaliando as contribuições dos choques relativos para as variações na taxa de desemprego agregado, na terceira coluna, nota-se que entre $40 \%$ e $60 \%$ do aumento da taxa de desemprego nos anos noventa pode ser atribuído a choques desse tipo, de acordo com o modelo. Choques relativos teriam contribuído com uma parte significativa do aumento do desemprego dos não-qualificados, entre $68 \%$ e $77 \%$, assim como dos semi-qualificados, cujas estimativas se situam entre $53 \%$ e $67 \%$. No caso dos trabalhadores qualificados os resultados apontam desde uma ligeira queda da taxa de desemprego a um aumento correspondente a $32 \%$ do aumento total.

Os efeitos de choques relativos com os parâmetros estimados a partir dos rendimentos por hora são apresentados na tabela 11 do apêndice B. Os resultados, nesse caso, também mostram impactos bastante acentuados para os trabalhadores não-qualificados e os semi-qualificados. Já a solução do modelo usando dados da PME, indica que entre $30 \%$ e $62 \%$ do aumento total da taxa de desemprego durante os anos noventa pode ser atribuído a desajustes entre a demanda e a oferta de trabalho por qualificação. Esses choques teriam contribuído com uma parcela entre $60 \%$ e $77 \%$ do aumento da taxa de desemprego dos não-qualificados, e entre $66 \%$ e $80 \%$ dos semi-qualificados. Trabalhadores qualificados teriam sido beneficiados por choques relativos com $\sigma=2,57$, mas com uma elasticidadesubstituição menor teria ocorrido um pequeno aumento do desemprego para esse grupo também.

Resumindo, os resultados estimados mostram que as mudanças na demanda relativa por trabalho qualificado tiveram um papel importante para o comportamento do desemprego relativo durante os anos noventa no Brasil. Além disso, uma parcela significativa do aumento do desemprego total é atribuída a choques desse tipo, de acordo com o modelo. Essas evidências são semelhantes às encontradas para outros países. Entretanto, o efeito estimado dos choques relativos sobre o desemprego no Brasil se mostra bastante intenso em comparação com os resultados de estudos internacionais (Nickell e Bell, 1995 e Manacorda e Petrongolo, 1999). Essa evidência parece estar associada ao baixo nível de qualificação da força de trabalho no Brasil, com uma grande parcela dos trabalhadores incapazes de se adaptar a métodos mais modernos de produção, e a intensidade das mudanças ocorridas na economia brasileira durante a década de noventa.

\section{CONCLUSÕES}

Entre 1990 e 1999 a taxa de desemprego no Brasil aumentou 5,4 pontos percentuais. Os aumentos foram mais acentuados para os trabalhadores semi-qualificados e principalmente para os nãoqualificados. Esse artigo procurou avaliar como choques agregados, choques relativos de produtividade e mudanças na composição da força de trabalho por qualificação influenciaram o comportamento da taxa de desemprego durante esse período. A análise foi baseada em um modelo com três tipos de trabalhadores (qualificados, semi-qualificados e não-qualificados). Usando dados anuais da PNAD, foram estimados os parâmetros do modelo e, dessa forma, calculados os impactos de cada um desses choques sobre o desemprego.

Os resultados mostram que choques agregados provocaram aumentos relativamente maiores na taxa de desemprego dos trabalhadores qualificados devido à maior rigidez salarial desse grupo. Portanto, choques agregados não parecem explicar as diferenças no comportamento do desemprego entre grupos de qualificação durante os anos noventa.

As mudanças na demanda relativa por trabalho qualificado parecem ter desempenhado um papel importante para as trajetórias do desemprego relativo. Com a utilização de tecnologias mais modernas após a liberalização comercial, a demanda por trabalhadores qualificados deve ter aumentado em relação aos semi-qualificados e aos não-qualificados. Por outro lado, a participação de trabalhadores qualificados na força de trabalho também aumentou consideravelmente, suavizando as conseqüências do primeiro efeito sobre o desemprego. 
De acordo com os resultados estimados, ocorreu uma queda acentuada na demanda por trabalhadores não-qualificados entre 1990 e 1999. Apesar da participação desse grupo na PEA ter diminuído, a taxa de desemprego aumentou quase 5 pontos percentuais como resultado de choques relativos. Esse aumento representa uma parte considerável da variação total na taxa de desemprego dos não-qualificados, que foi de 6,4 pontos percentuais durante esse período.

Embora a redução na demanda por trabalhadores semi-qualificados não tenha sido tão forte quanto a que incidiu sobre os não-qualificados, a participação desse grupo na PEA aumentou nos anos noventa. Esses dois efeitos resultaram em um grande aumento da taxa de desemprego dos trabalhadores semiqualificados, estimado entre 3,1 e 3,8 pontos percentuais. Esses valores representam mais da metade do aumento na taxa de desemprego desse grupo durante o período, que foi de 5,67 pontos percentuais.

As alterações na demanda relativa por trabalho foram favoráveis aos qualificados, mas esse efeito foi compensado pelo aumento na participação desse grupo na força de trabalho. As evidências encontradas para o resultado desses choques relativos foram tanto de aumento quanto de redução no desemprego desse grupo, dependendo do parâmetro de elasticidade-substituição.

Choques relativos também parecem ter sido importantes para o aumento do desemprego total durante a década de noventa. De acordo com os resultados, entre $40 \%$ e $60 \%$ da variação da taxa de desemprego entre 1990 e 1999 são atribuídos aos desajustes entre a demanda e a oferta de trabalho por qualificação.

\section{Referências Bibliográficas}

Arbache, J. \& Corseuil, C. (2004). Liberalização Comercial e Estruturas de Emprego e Salário. Revista Brasileira de Economia, 58(4):485-505.

Baltagi, B. \& Blien, U. (1998). The German Wage Curve: Evidence from the IAB Employment Sample. Economics Letters, 61(2):135-142.

Baltagi, B., Blien, U., \& Wolf, K. (2000). The East German Wage Curve: 1993-1998. Economics Letters, 69(1):25-31.

Barros, R. P. \& Mendonça, R. (1997). Flexibilidade do Mercado de Trabalho Brasileiro: uma Avaliação Empírica. Technical Report 452, IPEA.

Berg, J. \& Contreras, D. (2002). Is there a Wage Curve in Chile? mimeo.

Blanchflower, D. \& Oswald, A. (1995). An Introduction to the Wage Curve. Journal of Economic Perspectives, 9(3).

Blanchflower, D., Oswald, A., Bernanke, B., \& Rotemberg, J. (1994). The Wage Curve. Cambridge, MA: MIT Press.

Card, D. (1995). The Wage Curve. Journal of Economic Literature, 33(2):785-799.

Fernandes, R. \& Menezes-Filho, N. (2002). Escolaridade e Demanda Relativa por Trabalho. In MenezesFilho, N. \& Chahad, J., editors, O Mercado de Trabalho no Brasil, volume 1.

Gregg, P. \& Manning, A. (1997). Skill-Biased Change, Unemployment and Wage Inequality. European Economic Review, 41(6).

Hammermesh, D. (1993). Labor Demand. Princeton University Press.

Johnson, G. (1997). Changes in Earnings Inequality: The Role of Demand Shifts. Journal of Economic Perspectives, 11(2):41-54. 
Juhn, C., Murphy, K., Topel, R., Yellen, J., \& Baily, M. (1991). Why has the Natural Rate of Unemployment Increased over Time? Brookings Papers on Economic Activity, 1991(2):75-142.

Katz, L. \& Murphy, K. (1992). Changes in Relative Wages, 1963-87: Supply and Demand Factors. Quarterly Journal of Economics, 107(1).

Keane, M. \& Runkle, D. (1992). On the Estimation of Panel-Data Models with Serial Correlation When Instruments Are Not Strictly Exogenous. Journal of Business and Economic Statistics, 10(1).

Layard, R., Nickell, S., \& Jackman, R. (1991). Unemployment: Macroeconomic Performance and the Labour Market. Oxford University Press.

Manacorda, M. \& Petrongolo, B. (1999). Skill Mismatch and Unemployment in OECD Countries. Economica, 66.

Menezes Filho, N. \& Rodrigues, M. (2003). Tecnologia e Demanda por Qualificação na Indústria Brasileira. Revista Brasileira de Economia, 57(3).

Nickell, S. \& Bell, B. (1995). The Collapse in Demand for the Unskilled and Unemployment Across the OECD. Oxford Review of Economic Policy, 11(1).

Nickell, S. \& Bell, B. (1996). Changes in the Distribution of Wages and Unemployment in OECD Countries. American Economic Review, 86(2).

Phelps, E. \& Zoega, G. (1997). The Rise and Downward Trends of the Natural Rate. American Economic Review, 87(2).

Shapiro, C. \& Stiglitz, J. (1984). Equilibrium Unemployment as a Worker Discipline Device. American Economic Review, 74(3).

Wood, A. (1995). How Trade Hurt Unskilled Workers. Journal of Economic Perspectives, 9(3):57-80.

\section{A. DESCRIÇÃO DOS DADOS}

Pesquisa Nacional por Amostra de Domicílio (PNAD) Os dados da PNAD são calculados anualmente pelo IBGE, abrangendo todo o território brasileiro. Realizada normalmente no início de outubro, a pesquisa tem como período de referência a semana anterior à entrevista. Por ano são entrevistados cerca de 330.000 indivíduos em 100.000 domicílios. Neste trabalho, são utilizados dados da PNAD para as áreas urbanas entre 1990 e 1999, exceto para 1991 e 1994, anos em que a pesquisa não foi realizada. Estão incluídos na amostra os indivíduos entre 25 e 64 anos, participantes da PEA.

Com os dados da PNAD podem ser obtidas as seguintes variáveis: escolaridade, rendimento médio do trabalho principal, horas trabalhadas, gênero, idade, setor de atividade, posição na família, posição na ocupação e região de residência. De acordo com o maior grau educacional obtido, os indivíduos são classificados como: não-qualificados (entre 0 e 3 anos de estudo), semi-qualificados (entre 4 e 10 anos de estudos) e qualificados (com 11 anos ou mais de estudos).

Para compatibilizar as versões da PNAD da década de oitenta, de 1981 a 1990, com as da década de noventa, de 1992 a 1999, são considerados nos dois casos o mesmo critério para a definição de ocupação, que corresponde ao utilizado na década de oitenta. Nesse caso, trabalhadores não-remunerados que trabalhavam menos de 15 horas na semana não são considerados empregados. Caso estivessem procurando emprego, esses trabalhadores são classificados como desempregados. Trabalhadores ocupados em atividades para o próprio consumo ou na construção para o próprio uso também não são considerados empregados usando os critérios da década de oitenta. 
Pesquisa Mensal de Emprego (PME) A PME é realizada mensalmente pelo IBGE para as seis principais regiões metropolitanas do país (Belo Horizonte, Porto Alegre, Recife, Rio de Janeiro, Salvador e São Paulo). Assim como foi feito com a PNAD, foram utilizados apenas dados para os indivíduos entre 25 e 64 anos, para o período de 1990 a 1998. As variáveis utilizadas foram: taxa de desemprego, rendimento médio real e os totais de empregados e desempregados. Essas variáveis foram obtidas para os mesmos grupos educacionais descritos acima e para cada uma das seis regiões metropolitanas.

\section{B. RESULTADOS COM OS PARÂMETROS DAS CURVAS DE SALÁRIO OBTIDOS COM OS REN- DIMENTOS POR HORA}

Tabela 10 - Curvas de salário por nível de qualificação

\begin{tabular}{llll}
\hline & Não-qualificados & Semi-qualificados & Qualificados \\
\hline Variável & $(1)$ & $(2)$ & $(3)$ \\
\hline Log do Desemprego & $-0,0383(0,0408)$ & $-0.0460(0.0404)$ & $-0,0125(0,0256)$ \\
\hline Observações & 168 & 168 & 164 \\
Período & $1990-1999$ & $1990-1999$ & $1990-1999$ \\
$R^{2}$ & 0,84 & 0,89 & 0,90 \\
\hline
\end{tabular}

Variável dependente: log dos rendimentos por hora trabalhada. Amapá e Roraima foram excluídos por causa do pequeno número de observações nessas Unidades da Federação. Observações referentes a Tocantins foram agregadas a Goiás. Todas as regressões usam variáveis dummy de tempo. Cada observação é ponderada pela sua participação relativa na PEA no ano. Os erros-padrão robustos são mostrados entre parênteses. A estatística $\chi^{2}(7)$ corresponde ao teste de Hausman para os modelos com efeitos fixos e em primeira diferença.

Tabela 11 - Efeitos de choques agregados sobre a variação do desemprego por nível de qualificação1990:1999

\begin{tabular}{llll}
\hline & $\begin{array}{l}\sigma: \text { elasticidade substi- } \\
\text { tuição }\end{array}$ & $\frac{d u_{m}}{d u_{q}}$ & $\frac{d u_{n}}{d u_{q}}$ \\
\hline$(1)$ & 1,32 & 0,63 & 0,61 \\
\hline$(2)$ & 2,57 & 0,55 & 0,52 \\
\hline
\end{tabular}

Nota: os efeitos dos choques agregados são calculados imputando os valores dos parâmetros nas equações (6a) e (6b). 
Tabela 12 - Efeitos de choques relativos sobre o desemprego por nível de qualificação - 1990:1999

\begin{tabular}{|c|c|c|c|}
\hline & (1) & $(2)$ & (3) \\
\hline & $\begin{array}{l}\text { Variações dos parâme- } \\
\text { tros de produtividade } \\
(\%)\end{array}$ & $\begin{array}{l}\text { Variações no desem- } \\
\text { prego resultantes de } \\
\text { mudanças relativas } \\
\text { na produtividade } \\
\text { e na composição } \\
\text { da PEA (em pontos } \\
\text { percentuais) }\end{array}$ & $\begin{array}{l}\text { Participação dos cho- } \\
\text { ques relativos na vari- } \\
\text { ação da taxa de desem- } \\
\text { prego }(\%)\end{array}$ \\
\hline \multicolumn{4}{|l|}{ Não-qualificados } \\
\hline$\sigma=1,32$ & $-30,0$ & 4,8 & 74,4 \\
\hline$\sigma=2,57$ & $-17,4$ & 4,1 & 63,5 \\
\hline \multicolumn{4}{|l|}{ Semi-qualificados } \\
\hline$\sigma=1,32$ & $-6,7$ & 4,0 & 69,9 \\
\hline$\sigma=2,57$ & $-4,6$ & 3,2 & 56,6 \\
\hline \multicolumn{4}{|l|}{ Qualificados } \\
\hline$\sigma=1,32$ & 11,0 & 1,6 & 37,4 \\
\hline$\sigma=2,57$ & 6,9 & $-0,2$ & $-3,4$ \\
\hline \multicolumn{4}{|l|}{ Total } \\
\hline$\sigma=1,32$ & - & 3,4 & 62,4 \\
\hline$\sigma=2,57$ & - & 2,3 & 42,3 \\
\hline
\end{tabular}

Nota: os efeitos dos choques relativos são calculados imputando os valores dos parâmetros nas equações (9a), (9b) e (9c). 


\section{RESULTADOS OBTIDOS A PARTIR DAS INFORMAÇÕES DA PME}

Tabela 13 - Curvas de salário por nível de qualificação

\begin{tabular}{llll}
\hline & Não-qualificados & Semi-qualificados & Qualificados \\
\hline Variável & $(1)$ & $(2)$ & $(3)$ \\
\hline Log do Desemprego & $-0,099(0,07)$ & $-0,168(0,07)$ & $-0,037(0,09)$ \\
\hline Observações & 192 & 192 & 192 \\
Período & $90-98$ & $90-98$ & $90-98$ \\
$R^{2}$ & 0,349 & 0,460 & 0,508 \\
\hline
\end{tabular}

Variável dependente: log dos rendimentos por indivíduo. Os Erros-padrão robustos são mostrados entre parênteses. Todas as regressões usam variáveis dummy de tempo (ano) e dummies sazonais trimestrais. Cada observação é ponderada pela sua participação relativa na PEA no ano.

Tabela 14 - Efeitos de choques agregados sobre a variação do desemprego por nível de qualificação1990:1999

\begin{tabular}{llll}
\hline & $\begin{array}{l}\sigma: \text { elasticidade substi- } \\
\text { tuição }\end{array}$ & $d u_{m} / d u_{q}$ & $d u_{n} / d u_{q}$ \\
\hline$(1)$ & 1,32 & 0,40 & 0,49 \\
\hline$(2)$ & 2,57 & 0,36 & 0,45 \\
\hline
\end{tabular}

Nota: os efeitos dos choques agregados são calculados imputando os valores dos parâmetros nas equações (6a) e (6b). 
Tabela 15 - Efeitos de choques relativos sobre o desemprego por nível de qualificação - 1990:1999

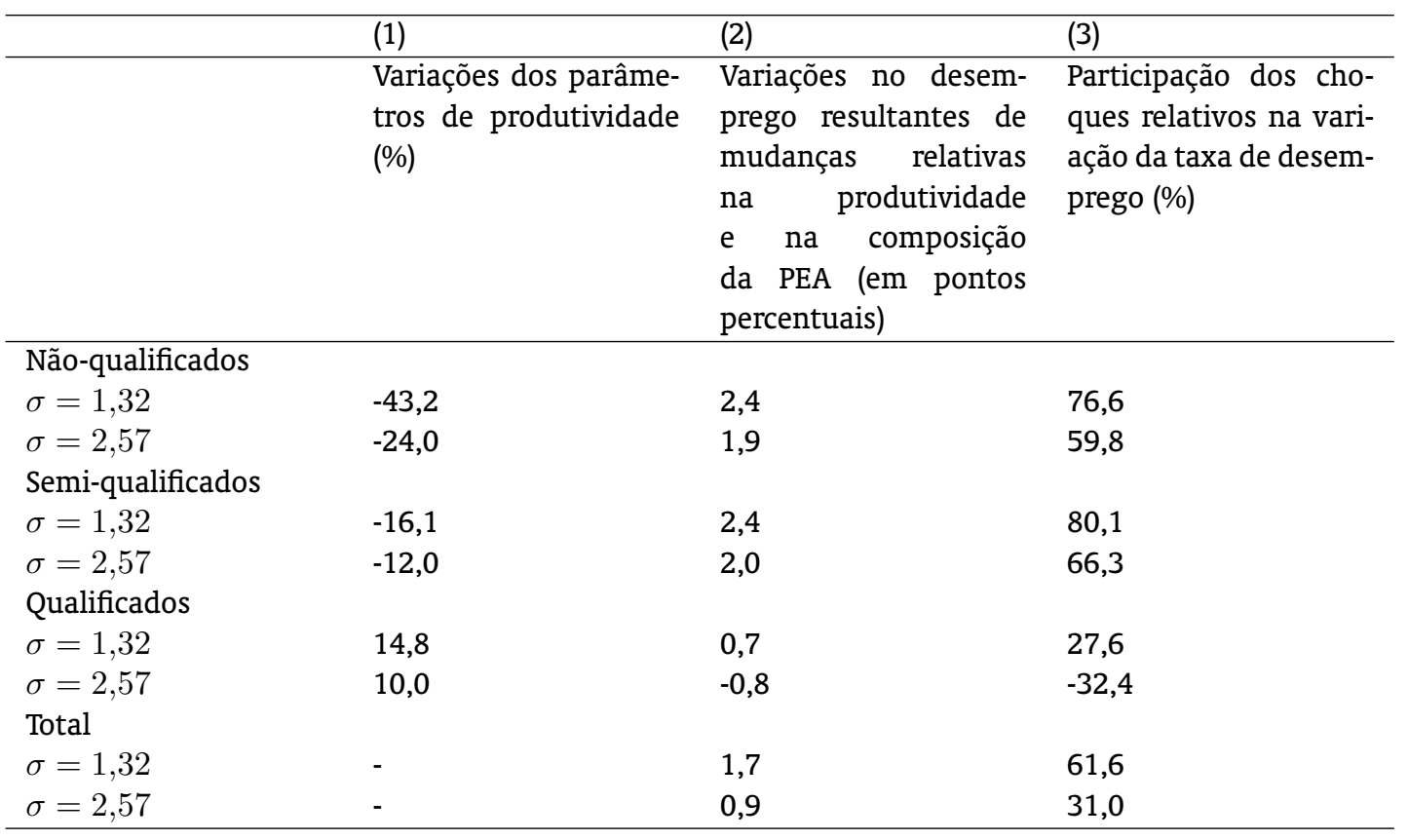

Nota: os efeitos dos choques relativos são calculados imputando os valores dos parâmetros nas equações (9a), (9b) e (9c). 